\title{
Analysis of Solar Cell Efficiency for Venus Atmosphere and Surface Missions
}

\author{
Geoffrey A. Landis ${ }^{1}$ \\ NASA John H. Glenn Research Center, Cleveland, OH 44135 \\ Emily Haag ${ }^{2}$ \\ Australia National University, Canberra Australia
}

\begin{abstract}
A simplified model of solar power in the Venus environment is developed, in which the solar intensity, solar spectrum, and temperature as a function of altitude is applied to a model of photovoltaic performance, incorporating the temperature and intensity dependence of the open-circuit voltage and the temperature dependence of the bandgap and spectral response of the cell. We use this model to estimate the performance of solar cells for both the surface of Venus and for atmospheric probes at altitudes from the surface up to $60 \mathrm{~km}$. The model shows that photovoltaic cells will produce power even at the surface of Venus.
\end{abstract}

\section{Nomenclature}

CFF = Solar cell curve fill factor (dimensionless)

GaAs the semiconductor gallium arsenide, used for solar cells

$\mathrm{GaInP}_{2}$ the ternary semiconductor gallium-indium phosphide, used as the top (wide bandgap) subcell of dualand triple-junction solar cells

$\mathrm{Ge}$ the elemental semiconductor germanium, used as the substrate on which high efficiency solar cells are deposited, and also the bottom junction of triple-junction solar cells

hc $\quad=$ Planck's constant times speed of light; constant for converting wavelength into energy $(J-n m)$

I/Io = Solar intensity at a given wavelength, scaled to intensity outside the atmosphere (dimensionless)

$\mathrm{I}(\lambda)=$ Solar intensity as a function of wavelength $\left(\mathrm{W} / \mathrm{m}^{2} / \mathrm{nm}\right)$

Isc $\quad=$ Solar cell short-circuit current (A)

$k=$ Temperature coefficient of voltage, $\mathrm{V} /{ }^{\circ} \mathrm{C}$

$\lambda=$ Wavelength (nanometers)

$Q E \quad=$ Quantum efficiency of a solar cell (electrons per photon)

$T \quad=$ Temperature $\left({ }^{\circ} \mathrm{C}\right)$

$\Delta T=$ Change in temperature from reference conditions $\left({ }^{\circ} \mathrm{C}\right)$

$V O C=$ Solar cell open-circuit voltage (V)

$\triangle V O C=$ Change in open-circuit voltage from reference conditions (V)

\footnotetext{
${ }^{1}$ NASA John Glenn Research Center, mailstop 302-1, 21000 Brookpark Road, Cleveland OH 44135. AIAA Assó Statdefieliesearcher, NASA Glenn Research Center. Australia National University, Canberra Australia.
} 


\section{Introduction}

\section{A. Missions to Venus}

The planet Venus, Earth's nearest neighbor, is an interesting planet that is the subject of many unresolved scientific questions. While many missions have orbited Venus, and a limited number have entered the atmosphere and even landed on the surface, to date all missions to the surface have been short, and none of the missions entering the Venusian atmosphere have operated on photovoltaic power.

Venus has a carbon-dioxide atmosphere with a pressure at the surface over ninety times that of the Earth at sealevel. Venus is continually covered in thick clouds, composed primarily of sulfuric acid droplets. The temperature in the Venus atmosphere increases as the altitude decreases toward the surface. At the surface, the temperature is over $450^{\circ} \mathrm{C}$.

Despite the hostile environment, there is significant interest in future missions to Venus, including both missions to probe the atmosphere of Venus, and missions to operate on the surface [1,2]. Proposed missions include landers and scientific stations to operate on the surface, high- and low-altitude balloons, and aircraft. Thus, the power systems needed for future Venus exploration may be desired for operation in a wide variety of environments, ranging from the high atmosphere to the surface.

Although radioisotope power sources have been proposed for use on the Venus surface [3-6], there is great interest in the possibility of photovoltaic power generation on Venus, due to the high cost and mass of radioisotope power systems. For small, low cost missions, such as weather stations or seismometers, only a few watts of power may be sufficient, and for such small, low cost missions, a photovoltaic power source could be an enabling technology,

In earlier work [7], a simple model of solar radiation on Venus was used to estimate performance of solar cells. In this work, a model of solar power in the Venus environment is developed which incorporates the solar intensity and solar spectrum, and applied to a measurement-based model of solar cell performance incorporating the temperature and intensity dependence of the open-circuit voltage, and the temperature dependence of the bandgap and spectral response. We use this model to estimate the performance of solar cells for both the surface of Venus and for atmospheric probes at altitudes from the surface up to the top of the main cloud layer.

\section{B. Challenges for Photovoltaics on Venus}

Above the main cloud layer, at altitudes greater than about $50 \mathrm{~km}$, Venus is a superb environment for the use of solar energy. At this altitude, balloon missions or high-altitude aircraft missions to investigate the atmosphere would have no difficulty getting sufficient power from solar arrays [8], assuming that the arrays are encapsulated against the environment. At lower levels, however, as the light levels decrease and the temperature increases, Venus becomes an increasingly difficult environment for the use of solar power. Determining whether it is reasonable, or even possible, to use solar power at such low elevations, and at the surface of Venus, will be the focus of this paper.

Four effects make the Venus environment challenging for operation of photovoltaic cells:

1. Solar intensity

2. Solar spectrum

3. Temperature.

4. Corrosive environment

In addition to the change of total insolation, the spectrum of the solar irradiance in the Venus atmosphere has a strong dependence on altitude. Shifts in spectrum mean that the optimum solar cell technology may be different at low altitudes and on the surface than the optimum choice above the atmosphere.

The Venus temperature also causes significant problems for operation of photovoltaic devices. Solar cells decrease in performance as temperature increases, and at very high temperatures can experience catastrophic degradation. Existing solar cells work poorly at high temperature. High-bandgap solar cells are least sensitive to temperature, but have their response primarily to the blue portion of the spectrum. However, the technologies for high-temperature operation of solar-cells is improving.

Finally, an additional challenge is the corrosive effect of the Venus environment, most notably the sulfuric acid droplets at the cloud level.

\section{Intensity and Spectrum}

Altitude on Venus are expressed in terms of elevation above the mean surface, or "datum." As on the Earth, the actual surface encompasses both mountains and plateaus at elevations higher than the datum, as well as basins and 
valleys at elevations lower than the datum. Elevations on Venus range high as 10.4 kilometers above the datum, at the peaks of Maxwell Montes in the near-polar regions of Lakshmi Terra.

The atmosphere of Venus is mostly clear above the cloud level, but as the altitude is reduced from $60 \mathrm{~km}$ above the datum to $50 \mathrm{~km}$, passing through the main cloud layer, the solar intensity becomes significantly attenuated. Cloud particles absorb and scatter the incident light, with mid-wavelength (visible) light penetrating somewhat more than the longer wavelength red and infrared light. Below the main clouds, the atmosphere is clear of aerosols, however, incident light is diffused away from the surface by scattering due to the atmosphere itself. This Rayleigh scattering selectively attenuates the shortest wavelength components of the spectrum, and hence the lower the altitude considered, the more the spectrum becomes deficient in the short wavelength portion of the spectrum.

\section{Temperature}

A significant difficulty of the Venus environment is the temperature. Figure 1 shows the temperature in ${ }^{\circ} \mathrm{C}$ as a function of altitude above the Venus mean surface. The surface temperature of about $460^{\circ} \mathrm{C}$ is significantly higher than the normal operating temperature of existing solar cells. Temperature does not significantly vary between day and night. As on Earth, temperature in the Venus atmosphere decreases with altitude, with a lapse of about $7.7^{\circ} \mathrm{C}$ per kilometer. At the highest points on the surface of Venus, $10.4 \mathrm{~km}$ above the datum, the temperature is $390^{\circ} \mathrm{C}$.

The performance decrease with temperature depends on the bandgap of the solar cell material chosen, and different technologies cells will have different performance in the Venus environment. The temperature also has a strong interaction with the spectrum, since the wide-bandgap semiconductors that are least sensitive to temperature are inherently most responsive to the short-wavelength illumination and are insensitive to red and infrared. Thus, the selection of technology is a trade-off between the higher performance of wide-bandgap semiconductors and the reduction of short-wavelength spectrum available.

Analysis of the use of solar cells for high-temperature operation has been a subject of interest for other applications and missions [9]. Testing shows that commercial triple-junction solar cells continue to operate at temperatures of $400^{\circ} \mathrm{C}$ without catastrophic degradation $[10,11]$. Thus, although the surface temperature of Venus will result in decreased performance, the temperature does not rule out the use of solar cells.

The temperature coefficient of solar cells depends on the open-circuit voltage, becoming more negative as the light intensity decreases. Thus, the low solar intensity below the Venus clouds has a double impact on the efficiency: not only decreasing the cell performance directly, but also making the cell more sensitive to temperature. On the other hand, the solar cell bandgap also decreases with temperature, moving the response toward longer wavelengths. Since the solar spectrum at the surface tends to be blue-deficient, the spectral response shift due to increased temperature tends to somewhat compensate for the blue-deficient spectrum.

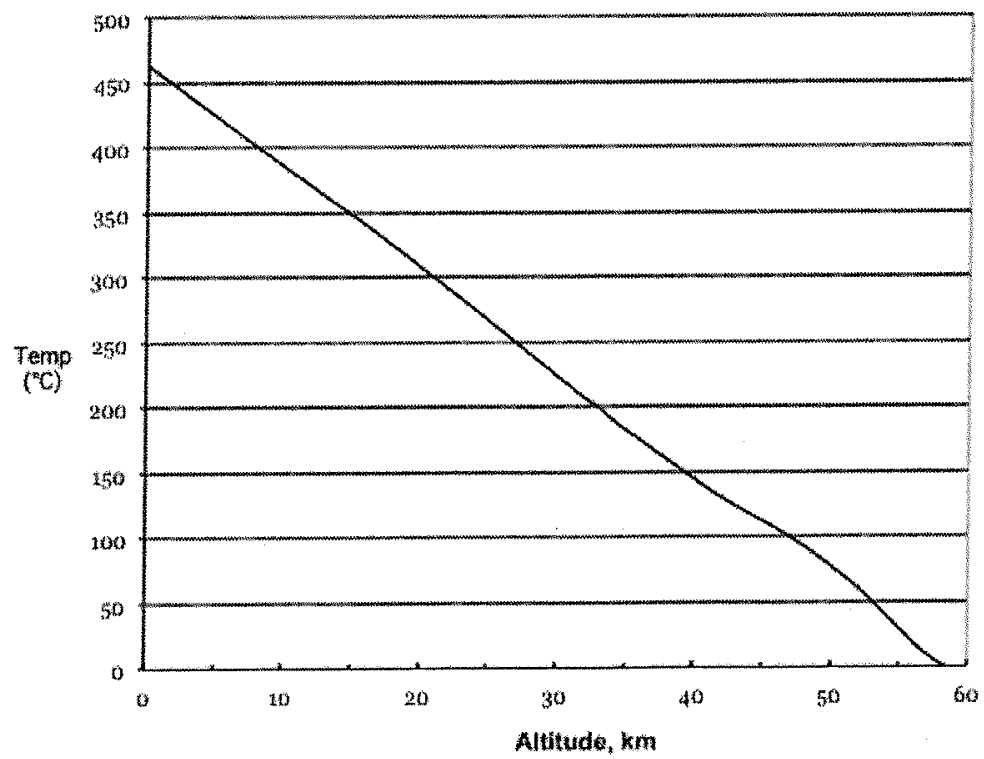

Figure 1: temperature in the Venus atmosphere $\left(\right.$ in ${ }^{\circ} \mathrm{C}$ ) as a function of altitude above the mean surface, or "datum"

American Institute of Aeronautics and Astronautics 


\section{Analysis}

\section{A. Method}

The analysis of solar cell performance on Venus was be done in a series of steps. First, an estimated spectrum of sunlight in the Venus atmosphere was calculated as a function of altitude:

1. Start with the exoatmospheric solar intensity and spectrum at Venus

2. Multiply by light transmission function of the atmosphere, $\mathrm{I} / \mathrm{L}$, using data from the Venera mission

Next, the short-circuit current of the solar cells was calculated as a function of the spectrum and temperature:

3. Calculate effect of temperature-induced shift of the solar cell spectral response

4. Calculate current of each junction by integrating the quantum efficiency across the (altitude dependent) spectrum)

5. (for multi-junction cells) determine which subcell limits multijunction cell current

Finally, the cell voltage was calculated as a function of the temperature and the intensity:

6. Calculate effect of intensity on voltage

7. Calculate temperature coefficient corrected for intensity

8. Calculate effect of temperature on voltage

From these components, the final performance can be calculated:

9. Calculate solar-cell output as a function of altitude,

\section{B. Exoatmospheric Solar Flux at Venus}

The exoatmospheric solar spectrum at Venus is assumed to be identical to the exoatmospheric solar spectrum at Earth orbit (referred to as Air-Mass Zero, or "AM0"), with the intensity multiplied by the inverse square of the distance from the sun. The exoatmospheric intensity used is $2600 \mathrm{~W} / \mathrm{m}^{2}$, slightly less than twice the intensity at Earth orbit. This will be referred to as "Venus AM0".

\section{Spectral Irradiance in the Venus Atmosphere}

Atmospheric spectral transmission data from the Venera 11 spectrophotometer [12] was used to calculate the solar spectrum. These measurements, in the form of $1 / 10$ (where Io is the exoatmospheric intensity), were taken with the sun $20^{\circ}$ from the zenith. The raw data is shown in figure 2 .

To integrate over the spectrum, the data were linearly interpolated between the measured wavelengths over the range of the measured data, 450 to 1000 nanometers. The data from the Venera mission did not extend below 450 nanometers, so for shorter wavelengths the graph of I/Io as a function of wavelength was linearly extrapolated at each altitude. Since there is almost no energy in the small amount of light near the surface in the wavelength range below 450 nanometers, the error introduced from linear extrapolation is expected to be small. Likewise, the spectrum was not measured at wavelengths longer than 1000 nanometers, and above this wavelength, the I/lo curve was assumed to be flat. Since, for the solar cells considered, only the bottom (Ge) subcell of the triple-junction cell has photoresponse at wavelengths longer than 1000 nanometers, and this is never the limiting subcell of the cell, the efficiency is not sensitive to the details of the extrapolation in this range.

The solar spectrum as a function of altitude is thus equal to the Venus AMO spectrum multiplied by the spectral intensity $\mathrm{l} / \mathrm{lo}$ as a function of altitude.

This calculated spectrum is shown in figure 3 . 


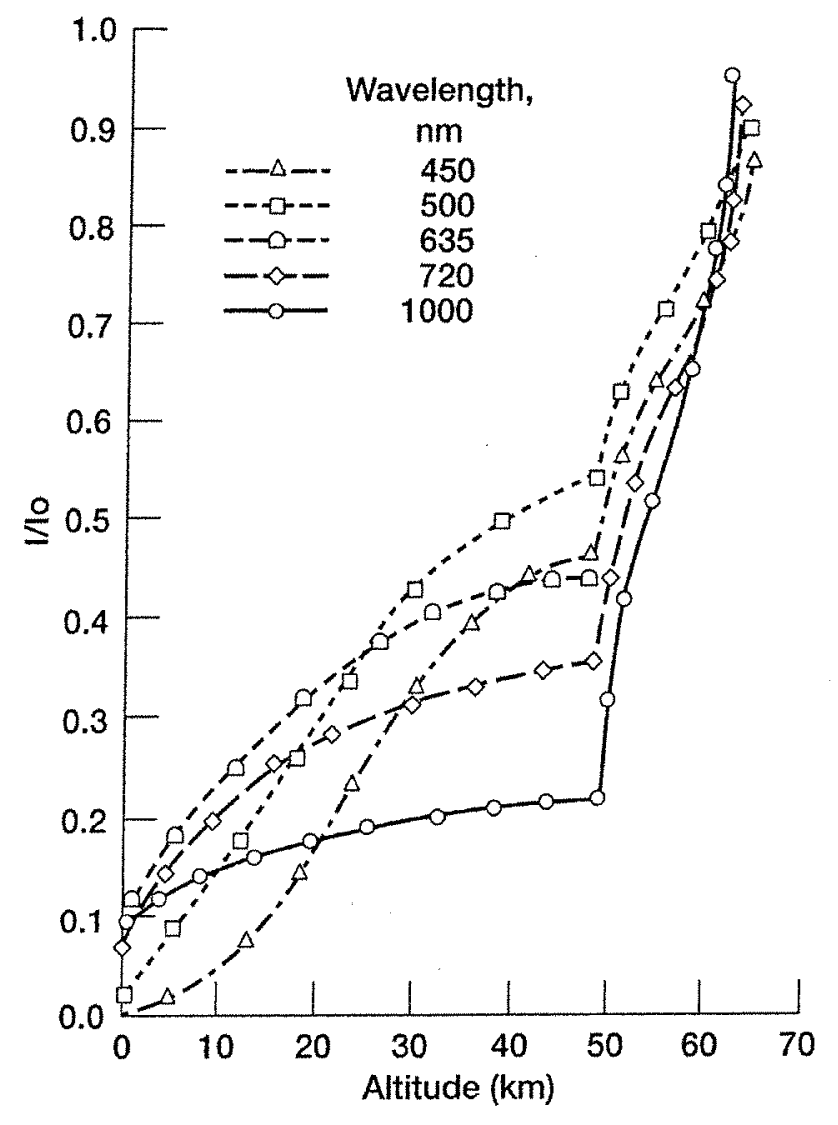

Figure 2: Venera data showing solar intensity I/Io as a function of altitude for five wavelengths



Figure 3: Solar spectrum in the Venus atmosphere 


\section{Temperature-induced Shift of Cell Spectral Response}

The calculated spectrum was then used to determine the short-circuit current of candidate solar cells. Three photovoltaic cell technologies were considered, characteristic of cells currently available. The three cell types considered were triple-junction ( $\mathrm{GaInP}_{2} / \mathrm{GaAs} / \mathrm{Ge}$ ), dual-junction (GaInP $2 / \mathrm{GaAs}$ ) and single-junction (GaAs) cells.

In multijunction solar cells, each of the series-connected junctions ("subcells") is constrained to have the same current. The three junctions have different spectral response, and hence the current of each will vary differently as a function of the varying spectrum in the Venus atmosphere. The current is limited by the current of the lowest current junction in the stack, while the voltage is the sum of the voltages of each subcell.

The current of each subcell is calculated from the spectral response, expressed in terms of the quantum efficiency (QE). Quantum efficiency indicates the number of electrons generated per incident photon, and is measured as a function of wavelength. It is dependent on a number of parameters of the cell, most significantly the bandgap of the semiconductor of which the solar cell is made. Since the bandgap of a semiconductor varies with temperature, the QE will also vary with temperature. For the calculation here, the QE of the individual subcells was measured at standard (room temperature) conditions, and the variation of bandgap with temperature was used to correct the measured $\mathrm{QE}$ curves to the temperature at the altitude.

Figure $4 \mathrm{~A}$ shows the effect of temperature on the quantum efficiency of the top ( $\left.\mathrm{GaInP}_{2}\right)$ subcell of a dual-or triple-junction stack. As can be seen, the main effect is to shift the long-wavelength cut-off toward longer wavelengths as temperature increases. This has the effect of increasing the photocurrent for the cell as the temperature rises.

Figure $4 \mathrm{~B}$ shows the effect of temperature on the quantum efficiency of the middle (GaAs) subcell of a multijunction stack. In this case the light reaching the GaAs subcell is filtered through the top GaInP $\mathrm{P}_{2}$ subcell, so the short-wavelength cut-on moves to progressively longer wavelength, as more and more light is absorbed by the top subcell. Like the top cell, the long-wavelength cut-off of the quantum efficiency also moves toward longer wavelengths with increasing temperature.

Finally, figure $4 \mathrm{C}$ shows the effect of temperature on the quantum efficiency of the bottom (Ge) subcell. The cell response includes more of the infrared as temperature increases. (Since this is not the limiting junction of the cell, the added current due to more conversion of infrared light is not useful.)

The quantum efficiency as a function of altitude is calculated from the temperature, as seen in figure 1. For any given altitude, the total current of each junction is then calculated from the spectrum and quantum efficiency by integrating over wavelength:

$$
I S C=\int \frac{h c}{\lambda} Q E(\lambda) \cdot I(\lambda) d \lambda
$$

To calculate the triple-junction cell current, the photocurrents of all three junctions were examined and the current was assumed to be limited by the lowest current-producing junction. These subcell currents are shown as a function of altitude in figure 5. As can be seen, the middle (GaAs) junction limits the current for nearly the whole range of altitudes, from the cloud level to just below $10 \mathrm{~km}$, at which point the deficiency of blue light means that the top $\left(\mathrm{GaInP}_{2}\right)$ junction begins to limit the current. Since at no altitude is the bottom $(\mathrm{Ge})$ cell limiting the current, the total current for a dual-junction cell (without the Ge subcell) is the same as the current for a triple-junction cell (with a Ge subcell).

To calculate the single-junction efficiency, the same procedure was used with the current from a single GaAs junction calculated from the (temperature dependent) quantum efficiency of a single-junction GaAs cell.

\section{Temperature- and Intensity-dependent Temperature Coefficient of Voltage}

Once the short-current current has been calculated, the open-circuit voltage (Voc) of each subcell is calculated, based on values measured at standard conditions. Since nominal open circuit voltage is measured under AMO (Earth orbit) intensity, the first correction needed to correct to the actual (effective) intensity. This correction is a logarithmic function of the short-circuit current. Note that at altitudes above $50 \mathrm{~km}$, the effective solar intensity is actually greater than the solar intensity at AM0, and so this correction is slightly positive. Below $50 \mathrm{~km}$, as the sunlight intensity decreases, the correction to Voc becomes negative.

The voltage is also dependent on the temperature. This temperature can be expressed in terms of the linear temperature coefficient, $\mathrm{k}$ (where $\mathrm{k}$ is a negative number, indicating voltage decreases with increasing temperature):

$$
\Delta \mathrm{Voc}=\mathrm{k} \Delta \mathrm{T}
$$

The temperature coefficient of voltage for a multi-junction cell will be the sum of the temperature coefficients of the individual subcells. 

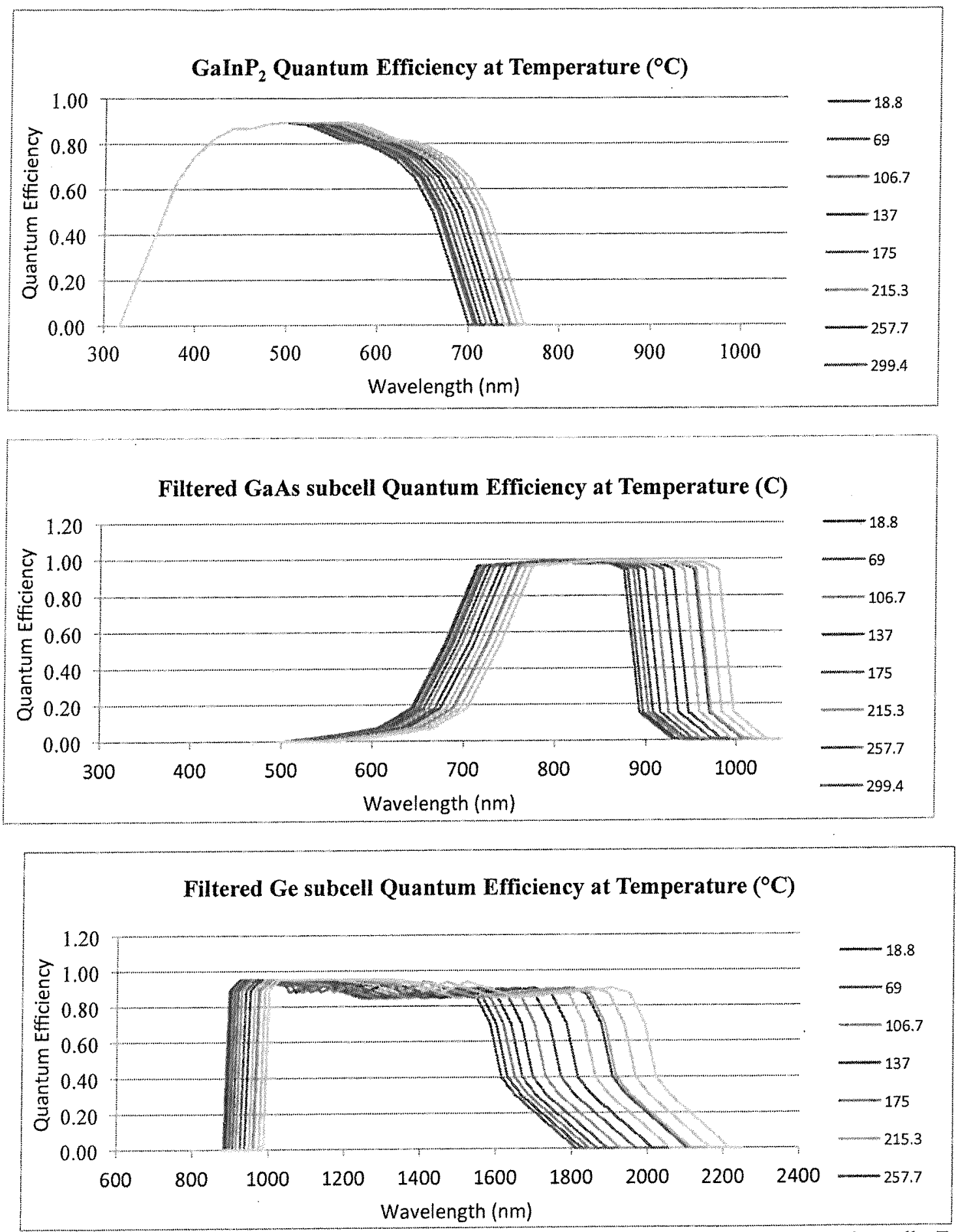

Figure 4: quantum efficiency as a function of temperature for the three subcells of a triple-junction cell. Top: $\mathrm{GainP}_{2}$ (top) subcell; center: GaAs (middle) subcell; bottom: Ge (bottom) subcell 


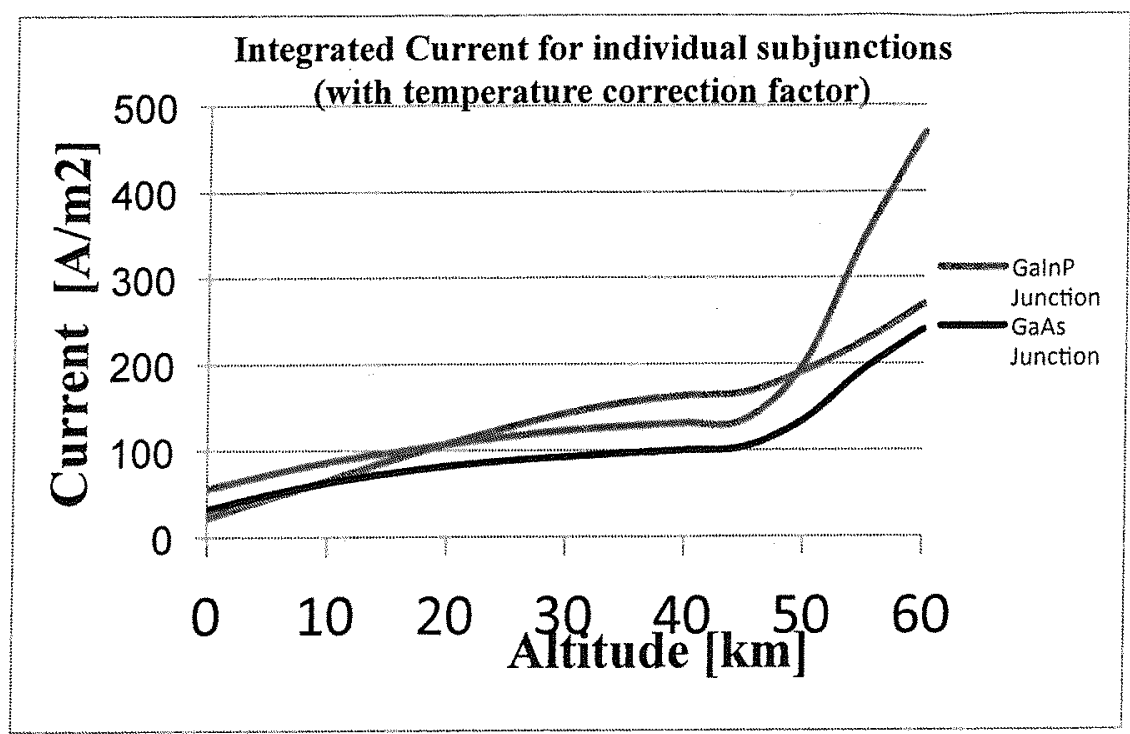

Figure 5: Calculated short-circuit current for each subcell of a triple-junction cell, including the Venus spectrum as a function of altitude and the temperature-related change in the spectral response.

Above the temperature where the $\Delta V O c$ of a subcell equals the open circuit voltage of the subcell, the contribution of that subcell to the voltage will equal zero. This causes a change in slope of the voltage/temperature relationship. Figure 5 shows an example of measured Voc for three examples of commercial triple-junction cells [from reference 11], taken up to a temperature of $400^{\circ} \mathrm{C}$. The Voc is a linear function of the voltage up to about $200^{\circ} \mathrm{C}$, at which point the curve has a change in slope, and is again linear (with decreased slope) above about $225^{\circ} \mathrm{C}$. The change in slope indicates the temperature at which the bottom (lowest voltage) junction, the Ge subcell, stops contributing to the total voltage. At this point, the triple-junction effectively has become a dual-junction cell.

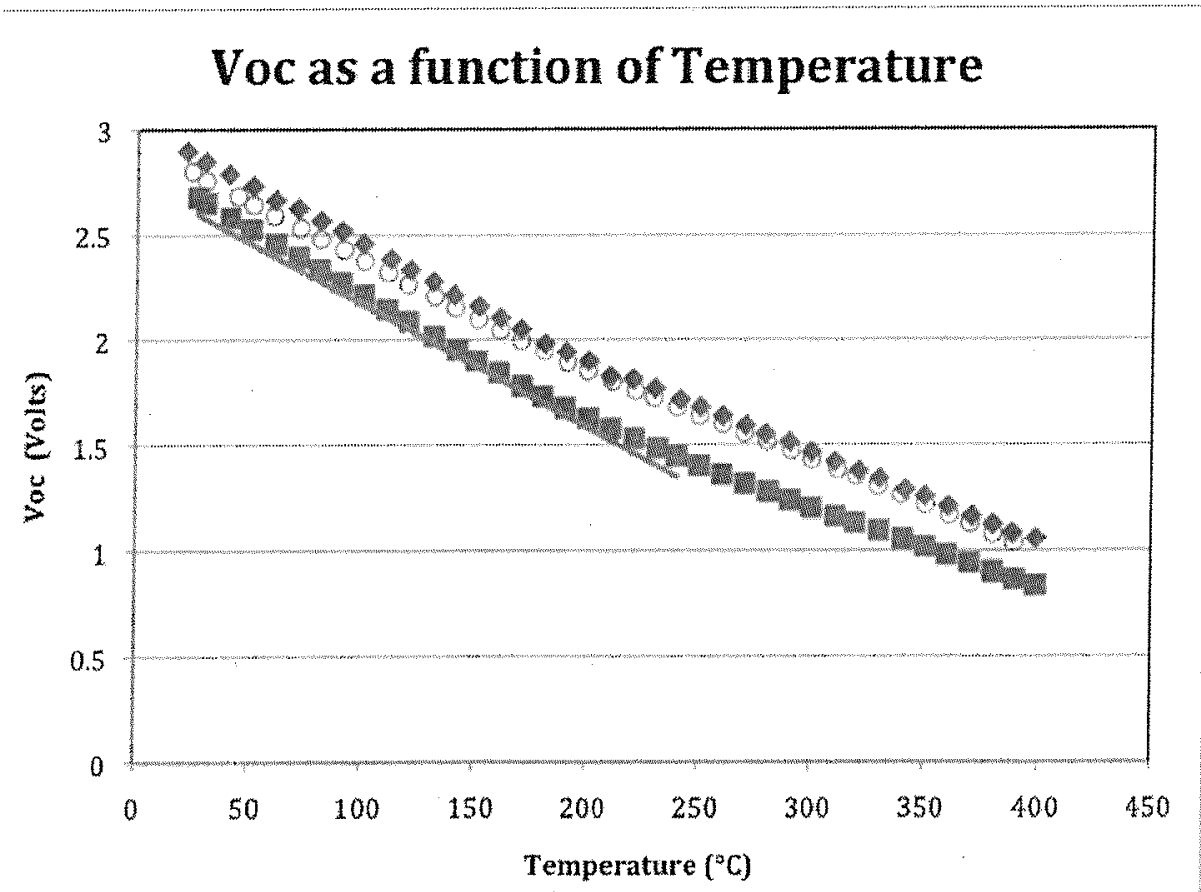

Figure 6: Experimental values of the effect of temperature on open-circuit voltage for commercially-available triple-junction cells. 
The temperature coefficient of voltage, however, is itself a function of the short-circuit current [11]. Thus, the measured temperature coefficients are corrected for the current, as calculated above, in order to calculate the open circuit voltage.

The power output of a cell is the product of the short-circuit current Isc, with the open-circuit voltage Voc, multiplied by the "curve fill factor," CFF, which accounts for the fact that the maximum-power operating point of the cell is not at short circuit current nor at open circuit voltage. Since for the high-efficiency cells examined here the variation in CFF with temperature is remains within narrow bounds, and this variation is much less than the variation in the Isc and Voc, the temperature variation of this term was neglected, and the CFF was assumed to be constant.

With these correction factors calculated, the expected power output as a function of altitude can be computed.

\section{Results}

\section{A. Choice of Cell Type}

The first question asked is, which type of solar cell is most efficient for operation at Venus? Three cell types were analyzed: a triple-junction cell, characteristic of high-efficiency space solar cells currently available; a dualjunction cell, assumed to be identical to the triple-junction solar cells but without the bottom (Ge) subcell; and a single-junction GaAs cell.

The triple junction solar cell has the highest efficiency outside the atmosphere, however, the Ge subcell cuts off at a temperature of $200-250^{\circ} \mathrm{C}$, while the top $\mathrm{GaInP}_{2}$ subcell becomes limited by the limited amount of blue light at the Venus surface. Since the GaAs cell is less dependent on the short wavelength portion of the spectrum, it was initially conjectured that a single-junction GaAs cell might be a better choice for the lowest altitudes.

However, the result of the analysis here shows that even at the surface, the single-junction GaAs solar cell does not outperform the triple-junction or dual-junction cell. The shift of bandgap with temperature allows the GaIn $\mathrm{P}_{2}$ junction to continue to perform all the way to the surface, and even though the $\mathrm{GaInP}_{2}$ junction does become the current-limiting junction very near the surface, the higher voltage of the $\mathrm{GaInP}_{2}$ junction slightly outweighs the restriction of current (although the performance of the two cell types becomes very similar near the surface.)

In the triple-junction cell, the bottom Ge junction turns off below an altitude of about $30 \mathrm{~km}$ above the surface. Above this altitude, the triple junction cell outperforms the dual junction cell (as well as the single-junction GaAs cell). Below this altitude, the performance of the triple- and dual-junction cells is identical, and hence there is no performance reason for choosing the dual-junction cell type over the triple.

\section{B. Performance Results for Triple Junction Cell}

Table 1 shows the results of the power model of a solar array incorporating triple junction solar cells, for altitudes from the surface to 60 kilometers in the Venus atmosphere. The array assumed here has an efficiency (at standard AM0 conditions) of $29 \%$; equivalent to a $32.2 \%$ efficient cell with $90 \%$ packing factor.

Column 1 shows the altitude (referenced to the mean surface of Venus)

Column 2 shows the temperature at that altitude. The cell operating temperature was assumed to equal the atmospheric temperature.

Column 3 shows the correction to open circuit voltage due to the intensity.

Column 4 shows the voltage-normalized conversion efficiency of the array, incorporating the effect of intensity and temperature on the voltage. (Note that this value is not of great significance, since the intensity is not standard.)

Column 5 shows the current factor: the amount of current produced by the cell, compared to the amount of current produced by the cell if it were above the atmosphere. This is the "effective" intensity of sunlight relative to the sunlight above the atmosphere, where "effective" indicated that it is weighted over the wavelengths of spectral response of the solar cell.

Column 6 is the "effective" conversion efficiency, the product of the voltage-normalized conversion efficiency and the current factor. "Effective" efficiency means that this is the power output of the array divided by the power input at the top of the atmosphere.

Column 7 indicates which of the subcell junctions limits the solar-cell current.

Finally, column 7 gives the power output, in watts per square meter. Note that this is for the sun near zenith, which is appropriate for sites near the equator, for times close to local (solar) noon. 


\begin{tabular}{|c|c|c|c|c|c|c|c|}
\hline $\begin{array}{c}\text { Altitude } \\
(\mathbf{k m})\end{array}$ & $\begin{array}{c}\text { Temp } \\
\left({ }^{\circ} \mathbf{C}\right)\end{array}$ & $\begin{array}{c}\text { Voc } \\
\text { Vintensity } \\
\text { Factor }\end{array}$ & $\begin{array}{c}\text { Voltage } \\
\text { Efficiency }\end{array}$ & $\begin{array}{c}\text { Current } \\
\text { Factor }\end{array}$ & $\begin{array}{c}\text { "Effective" } \\
\text { Efficiency }\end{array}$ & $\begin{array}{c}\text { Limiting } \\
\text { Layer }\end{array}$ & $\begin{array}{c}\text { Power } \\
\left.\mathbf{W} / \mathbf{m}^{2}\right)\end{array}$ \\
\hline 0 & 462 & 0.87 & $5.20 \%$ & $6.39 \%$ & $0.33 \%$ & Top & 8.7 \\
\hline 5 & 424 & 0.91 & $6.54 \%$ & $12.89 \%$ & $0.84 \%$ & Top & 22.0 \\
\hline 10 & 385 & 0.93 & $7.84 \%$ & $18.25 \%$ & $1.43 \%$ & Middle & 37.4 \\
\hline 15 & 378 & 0.94 & $8.18 \%$ & $21.33 \%$ & $1.75 \%$ & Middle & 45.6 \\
\hline 20 & 340 & 0.95 & $9.41 \%$ & $23.78 \%$ & $2.24 \%$ & Middle & 58.5 \\
\hline 25 & 299 & 0.96 & $10.75 \%$ & $25.59 \%$ & $2.75 \%$ & Middle & 71.9 \\
\hline 30 & 258 & 0.97 & $12.11 \%$ & $26.89 \%$ & $3.26 \%$ & Middle & 85.1 \\
\hline 35 & 215 & 0.97 & $13.49 \%$ & $28.08 \%$ & $3.79 \%$ & Middle & 99.0 \\
\hline 40 & 175 & 0.98 & $14.80 \%$ & $29.01 \%$ & $4.29 \%$ & Middle & 112.2 \\
\hline 45 & 137 & 0.98 & $23.06 \%$ & $30.09 \%$ & $6.94 \%$ & Middle & 181.4 \\
\hline 50 & 107 & 0.99 & $25.09 \%$ & $39.02 \%$ & $9.79 \%$ & Middle & 256.0 \\
\hline 55 & 69 & 1.01 & $27.65 \%$ & $55.95 \%$ & $15.47 \%$ & Middle & 404.4 \\
\hline 60 & 19 & 1.01 & $30.79 \%$ & $69.47 \%$ & $21.39 \%$ & Middle & 559.2 \\
\hline
\end{tabular}

Table 1: Calculation of the power of a triple-junction solar cell as a function of altitude above the Venus datum

The "effective" cell efficiency has been here defined as the power output of the cell at a given altitude in the Venus atmosphere divided by the exoatmospheric intensity at Venus. By defining the effective cell efficiency normalized to the spectrum above the atmosphere, the filtering by the atmosphere and the effect of temperature on the spectral response of the cell are both incorporated into the efficiency calculation, eliminating the requirement to calculate the power density of the incident light. Figure 7 shows this effective efficiency as a function of altitude. To convert this to power output, the effective efficiency is multiplied by the Venus exoatmospheric solar constant of $2600 \mathrm{~W} / \mathrm{m}^{2}$.

As can be seen, there is a significant advantage in operating a photovoltaic power system at higher elevations. This is due to the combined effect of lower temperature, higher total light level, and increased short wavelength light. The highest mountains on Venus, at Lakshmi Planum, are near the pole. However, for polar region, since the sun is never near the zenith, the calculation here is not applicable; in any case, the low sun angle makes the polar regions unsuitable for solar power. The highest elevations regions near the equator, such as Maat Mons $\left.(a t) .5^{\circ} \mathrm{N}\right)$ can have altitudes as high as $\sim 8 \mathrm{~km}$ above the datum. Regions of the plateau Aphrodite Terra, also near the equator, have elevations of $\sim 5 \mathrm{~km}$ above the datum. Operating a solar array at $5 \mathrm{~km}$, rather than $0 \mathrm{~km}$, would increase the power output by $250 \%$.

\section{Example}

Table 2 shows some calculations of the required array area for missions. The first example is a "high" power mission, with a required power of 215 watts (near solar noon, for a landing site near the equator). An example would a modest lander mission. The left column of table 2 shows the required area as a function of elevation. To product this power at the datum altitude would require a solar array 5 meters by 5 meters. Moving the landing site to an elevation of $5 \mathrm{~km}$ above the datum reduces this area to only 10 square meters; still a large array, although somewhat more manageable. 
For a mission floating above the surface (for example, a balloon-borne science platform), array sizes become considerably smaller.

The second example calculation is for an extremely small package. The right column of figure 2 shows the panel areas if the power required is only 1.5 watts. This might, for example, be enough to operate a miniature seismic station, or a surface weather station. The solar arrays would be used to charge high-temperature batteries [13], which would then be used to power brief "burst" communications at a very low duty cycle. In this case, the solar array sizes are somewhat more reasonable.

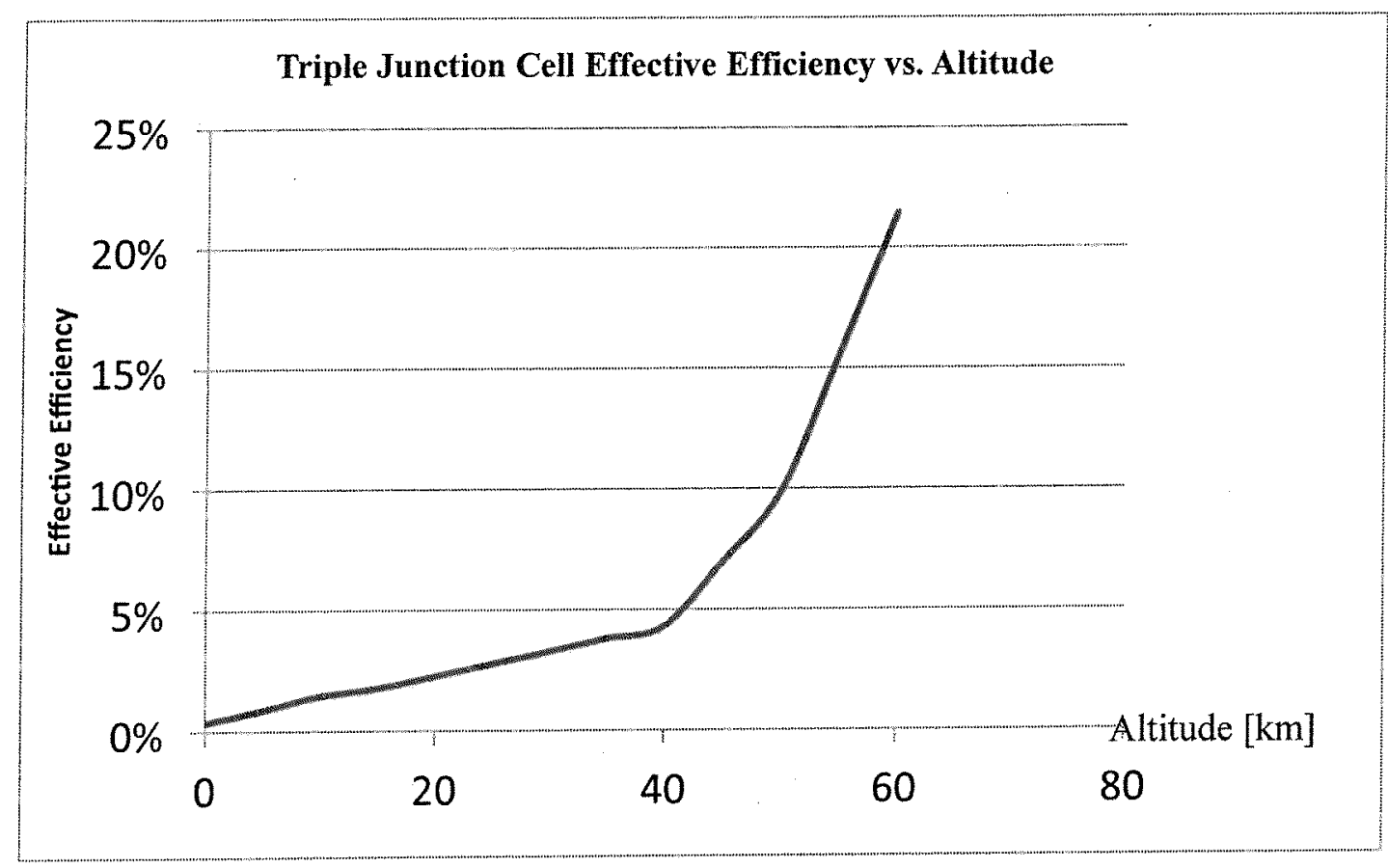

Figure 7: Effective Efficiency as a function of altitude.

\begin{tabular}{|c|c|}
\hline & $\begin{array}{c}\text { Lander/ } \\
\text { balloon }\end{array}$ \\
\hline Altitude & Panel Area \\
\hline $\mathbf{k m}$ & $\mathbf{m}^{2}$ \\
\hline 0 & 25 \\
\hline 5 & 10 \\
\hline 10 & 5.7 \\
\hline 15 & 4.7 \\
\hline 20 & 3.6 \\
\hline 25 & 3.0 \\
\hline 30 & 2.5 \\
\hline 35 & 2.2 \\
\hline 40 & 1.9 \\
\hline 45 & 1.2 \\
\hline 50 & 0.8 \\
\hline 55 & 0.5 \\
\hline 60 & 0.4 \\
\hline
\end{tabular}

\begin{tabular}{|c}
\hline $\begin{array}{c}\text { Seismometer/ } \\
\text { weather probe }\end{array}$ \\
\hline Panel Area \\
\hline $\mathbf{m}^{2}$ \\
\hline 0.17 \\
\hline 0.068 \\
\hline 0.040 \\
\hline 0.033 \\
\hline 0.026 \\
\hline 0.021 \\
\hline 0.018 \\
\hline 0.015 \\
\hline 0.013 \\
\hline 0.008 \\
\hline 0.006 \\
\hline 0.004 \\
\hline 0.003 \\
\hline
\end{tabular}

Table 2: Solar array sizes calculated for two example missions. Left: sizing for a "large" (215 watt) lander or balloon payload. Right: sizing for a hypothetical "small" (1.5 watt) seismic or weather station or balloon transponder. Calculations are high sun angles (i.e., noon near the equator).

American Institute of Aeronautics and Astronautics 


\section{Operation at Lower Sun Angles}

The solar spectrum and intensity data set used here is applicable only for the case where the sun is near the zenith. Accurate calculations for times or locations when the sun is at other elevations will require use of a more sophisticated optical scattering/absorption code, which was not used in this study. However, since the particles scattering light have high albedo (that is, the light is scattered more than absorbed), after the initial scattering, the light reaches the surface by a "random walk" trajectory, which does not have a strong dependence on the incident angle. In this case, the surface intensity for other sun angles should, to a rough approximation, follow a cosine dependence on sun angle.

\section{E. Environmental Effects}

Clearly, solar arrays for use on the surface of Venus must be encapsulated for operation in the high-temperature, corrosive environment. At the cloud level, the atmosphere contains sulfuric acid droplets. Encapsulation against corrosion by sulfuric acid is a known technology; for example, both glass and Teflon encapsulation are robust against sulfuric acid. Lower in the atmosphere, the sulfuric acid decomposes into $\mathrm{SO}_{3}$, (which is also corrosive). The temperature of $450^{\circ} \mathrm{C}$ is a higher temperature than the specified operating range of existing adhesives used to affix coverglass to solar array, although other types of advanced adhesives have been demonstrated at this temperature.

Overall, the problems of encapsulating, testing, and qualifying the arrays for operation in the Venus environment has not yet been examined in detail, and many issues remain to be addressed.

\section{Conclusions}

The surface and lower atmosphere of Venus is a poor place for the use of photovoltaic power systems, because of high temperatures, low light levels, and a spectrum that is deficient in the short-wavelength part of the spectrum. Nevertheless, testing has shown that existing solar cells continue to function without catastrophic degradation at temperatures up to $400^{\circ} \mathrm{C}$, equal to that found at the highest elevations of the Venus surface, and calculations show that while the amount of power produced by photovoltaic cells under the expected Venus solar spectrum is low, the power production is not zero. Solar arrays near the equator would produce about $8.7 \mathrm{~W} / \mathrm{m}^{2}$ at the average surface of Venus, and $22 \mathrm{~W} / \mathrm{m}^{2}$ at elevation of $5 \mathrm{~km}$ above the mean surface.

We conclude that photovoltaic panels could be used as a power source for missions to the surface of Venus.

\section{References}

1. NASA, Venus Science and Technology Definition Team, Venus Flagship Study Report: Final Report of the Venus Science and Technology Definition Team. JPL, April 17, 2009.

2. Venus Exploration Analysis Group, Venus Exploration Goals, Objectives, Investigations, and Priorities: 2007, 2007.

3. G. A. Landis and K. Mellott, "Venus Surface Power and Cooling System Design," paper IAC-04-R.2.06, Acta Astronautica, 61, No. 11-12, 995-1001 (Dec. 2007).

4. R. W. Dyson, P. G. Schmitz, L. B. Penswick, and G. A. Bruder, "Long-Lived Venus Lander Conceptual Design: How To Keep It Cool," paper AIAA 2009-4631, International Energy Conversion Engineering Conference (IECEC), Denver CO, August 2-5 2009.

5. R. W. Dyson and G. A. Bruder, "Progress Towards the Development of a Long-Lived Venus Lander Duplex System," paper AIAA 2010-6917, 8th International Energy Conversion Engineering Conference (IECEC), Nashville TN, July 25-28 2008; NASA/TM-2011-217018 (May 2009).

6. G. A. Landis, et. al., "Venus Rover Design Study," paper AIAA 2011-7268, AIAA Space 2011 Conference \& Exposition, Long Beach CA, Sept. 26-29, 2011.

7. G. A. Landis and T. Vo, "Photovoltaic Performance in the Venus Environment," 34th IEEE Photovoltaic Specialists Conference, Philadelphia PA, June 7-12, 2009.

8. G. A. Landis, C. LaMarre and A. Colozza, "Atmospheric Flight on Venus: A Conceptual Design," paper AIAA-2002-0819, Journal of Spacecraft and Rockets, Vol. 40, No. 5, 672-677 (Sept-Oct. 2003). 
9. G. A. Landis, "Solar Cells for High-Temperature Near-Sun Missions," 33rd IEEE Photovoltaic Specialists Conference, San Diego CA, May 12-16, 2008.

10. G. A. Landis, R. Jacobs and D. Scheiman, "Trade Studies of a Photovoltaic Power System for a Solar Probe," 34th IEEE Photovoltaic Specialists Conference, Philadelphia PA, June 7-12, 2009.

11. G. A. Landis, D. Belgiovani, and D. Scheiman, "Temperature Coefficient of Multijunction Space Solar Cells as a Function of Concentration," 37th IEEE Photovoltaic Specialists Conference, Seattle WA, June 19-24, 2011.

12. F. O. Fimmel, L. Colin, and E. Burgess, Pioneer Venus, NASA Report SP-461, 1983, p. 177.

13. G, A. Landis and R. Harrison, "Batteries for Venus Surface Operation," Paper AlAA-2008-5796, Journal of Propulsion and Power, 26, No. 4, 649-654, July/Aug 2010. 